\title{
Burnout, Workplace Violence and Social Support among Drivers and Conductors in the Road Passenger Transport Sector in Maputo City, Mozambique
}

\author{
Maria Tereza Couto ${ }^{1,2}$ and Stephen Lawoko ${ }^{1}$ \\ ${ }^{1)}$ Department of Public Health Sciences, Karolinska Institute, Sweden and ${ }^{2)}$ Faculty of Medicine, Eduardo Mondlane \\ University, Mozambique
}

\begin{abstract}
Burnout, Workplace Violence and Social Support among Drivers and Conductors in the Road Passenger Transport Sector in Maputo City, Mozambique: Maria Tereza Couto, et al. Department of Public Health Sciences, Karolinska Institute, Sweden-Objectives: Workplace violence is a work stressor which is presumed to lead to burnout, whereas social support is hypothesized to buffer the impact of such a stressor on health outcomes. In this study the association between burnout and workplace violence was investigated, and the role played by social support in moderating the relationship assessed. The study group consisted of workers in the road passenger transport sector in Maputo City, Mozambique. Methods: A random sample of 504 participants was selected from a register of 2,618 drivers and conductors working with road passenger transport. The study design was crosssectional. Previously validated measures of burnout, workplace violence and social support were used. Results: The prevalence of severe burnout was $3.6 \%$ and of mild burnout $30.1 \%$. Workplace violence was significantly associated with burnout after control for potential confounders. Burnout was more common among workers lacking social support following workplace violence than among peers who had received supported following an incident of violence. Conclusions: The study suggests that burnout is a public health problem among workers in the road passenger transport sector, and may be closely and independently linked to workplace violence. Social support appears to buffer or moderate the effect of workplace violence on burnout. This has implications for policy in the workplace. Strategies and guidelines
\end{abstract}

Received Jul 8, 2010; Accepted Feb 19, 2011

Published online in J-STAGE Apr 7, 2011

Correspondence to: M. T Couto, Karolinska Institute, Department of Public Health Sciences, Social Medicine, Norrbacka, Plan 2, 17176, Stockholm, Sweden

(e-mail:maria.couto@ki.se,couto@tdm.co.mz) are needed to support workers following workplace violence, since these may prove vital in reducing burnout and other psychosocial consequences.

(J Occup Health 2011; 53: 214-221)

Key words: Burnout, Bus driver, Social support, Workplace violence

Burnout is a psychological syndrome, a response to prolonged exposure to work-related stressors, and has three components: exhaustion, cynicism and reduced efficacy. Exhaustion refers to feelings of being overextended and depleted of emotional and physical resources. Cynicism (or depersonalization) refers to indifference or distant attitudes towards work, and reduced efficacy (or personal accomplishment) refers to a feeling of incompetence or lack of achievement and productivity at work $^{1,2)}$. Surveys have reported the prevalence of burnout as $2.5-51.1 \%$ in the health care sector ${ }^{3-5}, 2-34 \%$ in the education sector ${ }^{6,7)}, 51.4 \%$ in the justice sector ${ }^{8)}$, and $3-39 \%$ in the forest industry ${ }^{9}$.

Burnout has significant consequences for employees, in forms such as anxiety, depression, sleep disturbances, headache, gastrointestinal illness, hypertension, muscle tension, chronic fatigue, and poor job performance. It also has consequences for employing organizations, in forms such as absenteeism and high job turnover ${ }^{10-12)}$.

Burnout has been placed in a theoretical framework, in which factors inherent to the psychosocial work environment, socio-demographic/occupational characteristics, social relations outside work, lifestyle factors, and aspects of personality are all purported to affect its likelihood ${ }^{11)}$. High workload, role conflict and ambiguity, low predictability, lack of participation or social support, experienced unfairness and inadequate monetary compensation have been identified as work characteristics associated with an increased risk of burnout ${ }^{1,2,3,14)}$. There is also evidence that demographic characteristics, such as 
age, gender, education and marital status, may also be associated with the syndrome ${ }^{15-17)}$, and this evidence suggests older married workers, of female gender, with low education status are the most vulnerable.

Recently, surveys have indicated that workplace violence (WPV) may be associated with burnout ${ }^{18,19)}$, although the direction of causality remains unclear, i.e. whether WPV leads to burnout or whether burnout predisposes workers to violence. Work stressors (e.g. WPV) are assumed to lead to burnout, although it has been hypothesized that social support may buffer the effect ${ }^{20)}$. Theoretically, social support is embedded within a stress and coping framework, where the former is regarded as resulting from inadequate coping responses to threatening life events ${ }^{21,22)}$. Social support is believed to alleviate or buffer the impact of stress, e.g. by promoting problemsolving strategies that might reduce the allostatic load that has negative effects on health ${ }^{21)}$. As well as buffering effects, social support is presumed to have direct effects on health. For example, support networks are believed to provide regular rewarding experiences, which promote positive effects, and it is claimed that such emotionally induced experiences prevent dysregulation of the allostatic system $^{20,23)}$. Social support can be instrumental (e.g. financial assistance or the provision of resources to change the environment), informational (e.g. advice), or emotional (e.g. appreciation or appraisal) ${ }^{24)}$.

Although there are many studies of work-related stressors and their associations with burnout and social support, there is a shortage of such studies in a SubSaharan African context and, in particular, a lack of studies of the road passenger transport sector in Mozambique. Recently, a study from Mozambique has indicated that WPV is a common phenomenon in road passenger transport, with as many as $64 \%$ of workers having reported abuse in recent years ${ }^{25}$. This study furthers the analysis of WPV in this context (Mozambique) by investigating whether burnout and WPV are related, and whether social support moderates the relationship between them. More specifically, we address the following research questions: a) What is the extent of burnout in the road passenger transport sector in Maputo City, Mozambique? b) Does the prevalence of burnout differ between workers who have experienced WPV and peers who have not? c) Is availability of social support to workers exposed to WPV related to a lower prevalence of burnout?

\section{Methods}

\section{Setting and participants}

This study was conducted in Maputo City, the capital of Mozambique. It has a population of over a million in an area of $300 \mathrm{~km}^{2}$. . Road passenger transport is provided by buses, minibuses and taxis, owned by the government and private associations. The buses and minibuses have a driver and a conductor, while the taxis have a driver only. Drivers and conductors are registered at the National Traffic Institute (NTI), a government institution responsible for traffic control and regulation. The total number of NTI-registered drivers and conductors in Maputo City is 2,618, with the following distribution: 405 bus drivers, 377 bus conductors, 743 minibus drivers, 743 minibus conductors, and 350 taxi drivers. Registered drivers and conductors are predominantly male.

A pilot study of 50 participants indicated a WPV prevalence rate of $74 \%$. The results of the pilot study suggested that a sample of 504 would be adequate for the study, and 504 participants were selected at random from the NTI database (144 minibus drivers, 144 minibus conductors, 72 bus drivers, 72 bus conductors, 72 taxi drivers).

Most participants were aged 20-29 yr (37.9\%), married/ cohabitant $(57.9 \%)$, with a primary school or equivalent education (46.8\%), and literate (75\%). Minibus drivers and conductors jointly constituted $28.6 \%$ of the sample, and $14.7 \%$ had a supervisory position. All participants were male. Other characteristics of the participants are presented elsewhere ${ }^{25)}$.

\section{Design and procedure}

The study design was cross-sectional. The original questionnaire in English was translated into Portuguese, the official language of Mozambique, and a translation back into English was performed to check the Portugese wording. The questionnaire covered socio-demographic characteristics, access to information, literacy level, occupational experience, organizational changes, work environment, work conditions, health conditions, quality of life, lifestyle, and WPV reactions, consequences and burnout. For the current study, the items concerning WPV, burnout, access to social support, occupational experience, work-related stressors, socio-demographic characteristics and literacy level were of primary interest. Data were collected during eight consecutive weeks by three trained interviewers. The interviewers' training package included understanding the study aims, questionnaire content and administration, and ethical issues, such as respect for privacy, while performing the interviews. There was an emphasis on confidentiality and voluntary participation.

Addresses and telephone contacts were obtained from the records of the private transport associations and the government company. Participants were contacted at work or at home. When contacted, participants were offered an incentive package promising referral to a government hospital if they presented with psychological and/or physical symptoms resulting from violence or with any other cause. The participants had already been informed of the pending study, by their association or the administrator of the government company. All participants responded to the questionnaire (response rate: 100\%).The National Committee of Bioethics for Health in Mozambique 
approved the study.

\section{Measures}

1) Dependent variable

Burnout was the outcome of interest in this study, and was assessed using the Maslach Burnout InventoryGeneral Survey (MBI-GS) ${ }^{27}$. The MBI-GS consists of 16 items in 3 dimensions: exhaustion (5 items), cynicism (5 items), and reduced professional efficacy (6 items). The instrument has been previously validated ${ }^{27-29)}$. Responses were scored on a 0-6 point scale (never $=0$, a few times a year or less $=1$, once a month or less $=2$, a few times a month $=3$, once a week $=4$, a few times a week $=5$, every day=6). High scores on exhaution and cynicism and low scores on professional efficacy are an indication of burnout. Following Ahola et al. ${ }^{12)}$, the total score was calculated, with exhaustion, cynicism and reduced professional efficacy being given different weights in the summation $(0.4 \times$ exhaustion $+0.3 \times$ cynicysm $+0.3 \times$ reduced professional efficacy). The categorization of burnout and its three dimensions were based on the approximate frequency of symptoms: no symptoms (sum score 0 to 1.49 ), mild symptoms (sum score 1.50 to 3.49 ), and severe symptoms (sum score 3.50 to 6). No burnout was assigned to cases who experienced symptoms only a few times a year or never, mild burnout was assigned to monthly symptoms, and severe burnout was assigned to weekly or daily symptoms ${ }^{9,12,17,30)}$. More details on the instruments and scoring have been presented elsewhere ${ }^{9,12,17,27,30)}$.

2) Independent variables

Workplace violence (WPV) and social support were assessed using a previously validated questionnaire, the Violent Incident Form (VIF), which is widely used in developed countries ${ }^{31,32)}$. The questionnaire was adapted to reflect the road transport sector following a pilot study.

Workplace violence was assessed by questions probing whether participants had ever or during the past $12 \mathrm{mo}$ experienced a verbal threat/aggression, been bitten, slapped, hit, pushed, spat at, scratched, pinched, punched, kicked, or faced any unpleasant experience at work (as perceived by the participant). The response alternatives were "no", "yes, once or twice", and "yes, several times". Any "yes" response was operationalized as being exposed to violence.

Social support was assessed by asking participants exposed to WPV to indicate whether they had received social support after a violent incident. Possible responses were "yes", "no", and "felt no need for help". If "yes", participants were further asked to indicate from whom support had been received. The response alternatives were "supervisor", "co-worker" and "someone outside the workplace".
3) Possible confounding factors

Since demographic, occupational and other workrelated factors may be associated with both burnout and WPV, they were regarded as possible confounders, and therefore controlled for in the multivariate analyses. These variables were:

Occupational experience, which was assessed using questions regarding number of years working in the transport sector, number of years working in the present workplace, and whether the participant had a supervisory position.

Work-related stressors, were assessed using the Swedish Demand-Control-Support Questionnaire-DCQ ${ }^{33)}$, which assesses work-related demands (5 items), control (5 items) and support (6 items). The items for demand and control are scored on a 1-4 point scale (often $=4$, sometimes $=3$, seldom $=2$, never/almost never $=1$ ). Cronbach's alpha coefficients for the two first scales were 0.45 and 0.54 , respectively. The items for support are also scored on a $1-4$ point scale (strongly agree $=4$, mildly agree $=3$, mildly disagree $=2$ strongly disagree $=1$ ), and the Cronbach's alpha coefficient for this scale was 0.84 . Individual scores on the three subscales were calculated by summing the items on each subscale. The resulting sums are on a continuous scale. Higher scores indicate, higher work demands, control and support ${ }^{33)}$.

Socio-demographic characteristics were assessed using indicators such as age, marital status, highest educational level, occupation, and literacy level.

4) Statistical analyses

The SPSS for Windows, version 17.0, software package was used for all analyses. Chi-square tests were used to assess the associations between the dependent variable and categorical independent variables. Student's $t$-test was used to study the association between burnout and work stressors. Logistic regression was employed to examine the independent association between burnout and exposure to workplace violence after controlling for demographic characteristics and work stressors. The Hosmer and Lemeshow test was used to examine the goodness-of-fit of the logistic regression model.

\section{Results}

Prevalence of burnout in the road passenger transport sector by demographics, literacy level, occupational experience and WPV over the past 12 mo

The proportions of participants with severe and mild burnout were 3.6 and $30.1 \%$, respectively. In Table 1, mild and severe burnouts are aggregated. As shown in the table, age, marital status, occupational category and exposure to WPV over the past 12 mo were significantly associated with burnout. The proportion of burnout was highest in the age group $>60 \mathrm{yr}(81.8 \%)$, and the proportions among the age groups of 30-39, 40-49 and 50-59 yr were equally high (40.1, 42.0 and $42.4 \%$, 
Table 1. Proportion of participants with burnout by socio-demographic characteristics, work-related stressors, literacy level, and exposure to workplace violence over the past $12 \mathrm{mo}$

\begin{tabular}{|c|c|c|c|}
\hline & Total number & Number with mild/severe burnout & Proportion $(\%)$ \\
\hline \multicolumn{4}{|l|}{ Age $* * *$} \\
\hline$<20 \mathrm{yr}$ & 97 & 24 & 24.7 \\
\hline $20-29 \mathrm{yr}$ & 190 & 50 & 26.3 \\
\hline $30-39 \mathrm{yr}$ & 121 & 51 & 42.1 \\
\hline $40-49 \mathrm{yr}$ & 50 & 21 & 42.0 \\
\hline $50-59 \mathrm{yr}$ & 33 & 14 & 42.4 \\
\hline$>60 \mathrm{yr}$ & 11 & 9 & 81.8 \\
\hline \multicolumn{4}{|l|}{ Marital status** } \\
\hline Single & 147 & 38 & 25.9 \\
\hline Married/cohabitant & 290 & 101 & 34.8 \\
\hline Divorced/separated & 44 & 17 & 38.6 \\
\hline Widower & 21 & 13 & 61.9 \\
\hline \multicolumn{4}{|l|}{ Education } \\
\hline Less than primary school & 115 & 37 & 32.2 \\
\hline Primary school/similar & 235 & 73 & 31.1 \\
\hline Upper secondary school/university & 152 & 59 & 38.8 \\
\hline \multicolumn{4}{|l|}{ Occupation*** } \\
\hline Bus driver & 72 & 46 & 63.9 \\
\hline Bus conductor & 72 & 37 & 51.4 \\
\hline Minibus driver & 143 & 24 & 16.8 \\
\hline Minibus conductor & 143 & 24 & 16.8 \\
\hline Taxi driver & 72 & 38 & 52.8 \\
\hline \multicolumn{4}{|l|}{ Occupational experience } \\
\hline \multicolumn{4}{|l|}{ Years employed in passenger transport } \\
\hline $0-5 \mathrm{yr}$ & 178 & 64 & 36.0 \\
\hline $6-10 \mathrm{yr}$ & 205 & 68 & 33.2 \\
\hline $11-15 \mathrm{yr}$ & 86 & 27 & 31.4 \\
\hline$>15 \mathrm{yr}$ & 33 & 10 & 30.3 \\
\hline \multicolumn{4}{|l|}{ Years in present workplace } \\
\hline $0-5 \mathrm{yr}$ & 369 & 120 & 32.5 \\
\hline $6-10 \mathrm{yr}$ & 115 & 46 & 40.0 \\
\hline $11-15 \mathrm{yr}$ & 15 & 3 & 20.0 \\
\hline$>15 \mathrm{yr}$ & 3 & 0 & 0 \\
\hline \multicolumn{4}{|l|}{ Have any supervisory position } \\
\hline Yes & 74 & 28 & 37.8 \\
\hline No & 428 & 141 & 32.9 \\
\hline \multicolumn{4}{|l|}{ Literacy level } \\
\hline Can read & 378 & 126 & 33.3 \\
\hline Can't read & 124 & 43 & 34.7 \\
\hline \multicolumn{4}{|l|}{$\begin{array}{l}\text { Exposure to workplace violence over } \\
\text { the past } 12 \mathrm{mo}^{*}\end{array}$} \\
\hline No & 179 & 46 & 25.7 \\
\hline Yes, once or twice & 179 & 77 & 43.0 \\
\hline Yes several times & 144 & 46 & 31.9 \\
\hline
\end{tabular}

$* p$-value $<0.05 ; * * p$-value $<0.01 ; * * * p$-value $<0.001$.

respectively). Bus drivers suffered burnout to a greater degree than other occupational categories even though the majority of taxi drivers and bus conductors presented with symptoms (52.8 and 51.4\%, respectively). In addition, the proportions of burnout were higher among participants exposed to WPV (31.9 and $43.0 \%$, respectively) than 
Table 2. Associations between burnout and work-related stressors

\begin{tabular}{lccccc}
\hline Variable & Mean & Std. deviation & $t$-value & Degree of freedom (df) & $p$-value \\
\hline Demands (scale 5-20) & & & & 502 & 0.733 \\
$\quad$ No burnout ( $\mathrm{n}=333)$ & 11.10 & 2.379 & -0.341 & & \\
$\quad$ With burnout (n=169) & 11.01 & 2.541 & & 502 & $<0.001$ \\
Control (scale 6-24)*** & & & & \\
$\quad$ No burnout (n=333) & 14.81 & 2.671 & -5.521 & & \\
$\quad$ With burnout (n=169) & 13.48 & 2.730 & & & \\
Support (scale 6-24) & & & & \\
$\quad$ No burnout (n=333) & 19.58 & 3.757 & -1.581 & & \\
$\quad$ With burnout $(\mathrm{n}=169)$ & 19.01 & 4.061 & & & \\
\hline
\end{tabular}

$* * * p$-value $<0.001$.

Table 3. Logistic regression analysis of burnout: Odds ratios assessing the independent contribution of workplace violence after adjusting for age, marital status, occupation and work stressors

\begin{tabular}{|c|c|c|c|}
\hline Variable & Odds ratio $(\mathrm{OR})$ & $95.0 \%(\mathrm{CI})$ & $p$-value \\
\hline \multicolumn{4}{|l|}{ Age } \\
\hline$<20 \mathrm{yr}$ & 0.243 & $0.039-1.506$ & 0.128 \\
\hline $20-29 \mathrm{yr}$ & 0.210 & $0.039-1.117$ & 0.067 \\
\hline $30-39 \mathrm{yr}$ & 0.359 & $0.070-1.852$ & 0.221 \\
\hline $40-49 \mathrm{yr}$ & 0.280 & $0.051-1.529$ & 0.142 \\
\hline $50-59 \mathrm{yr}$ & 0.195 & $0.034-1.119$ & 0.067 \\
\hline$>60 \mathrm{yr}$ & reference & & \\
\hline \multicolumn{4}{|l|}{ Marital status } \\
\hline Single & 0.267 & $0.080-0.888$ & $<0.05$ \\
\hline Married/cohabitant & 0.297 & $0.101-0.876$ & $<0.05$ \\
\hline Divorced/separated & 0.468 & $0.134-1.638$ & 0.235 \\
\hline Widower & reference & & \\
\hline \multicolumn{4}{|l|}{ Occupation } \\
\hline Bus driver & 1.793 & $0.840-3.828$ & 0.132 \\
\hline Bus conductor & 1.170 & $0.493-2.778$ & 0.722 \\
\hline Minibus driver & 0.222 & $0.105-0.471$ & $<0.001$ \\
\hline Minibus conductor & 0.265 & $0.111-0.637$ & $<0.01$ \\
\hline Taxi driver & reference & & \\
\hline \multicolumn{4}{|c|}{ Workplace violence over past 12 mo } \\
\hline No & 0.533 & $0.301-0.941$ & $<0.05$ \\
\hline Yes, once or twice & 1.038 & $0.612-1.761$ & 0.890 \\
\hline Yes, several times & reference & & \\
\hline \multicolumn{4}{|l|}{ Work environment } \\
\hline Control & 0.906 & $0.836-0.981$ & $<0.05$ \\
\hline
\end{tabular}

Goodness-of-fit: Chi-square $=9.067, p$-value $=0.337$.

among unexposed peers $(25.7 \%)$. The associations between burnout and age, marital status, occupational category and workplace violence all reached statistical significance (at $p<0.001, p<0.01$ or $p<0.05$ ) using a chisquare test. There was no statistical significance for the associations between burnout and education, occupational experience, or literacy level.
Associations between burnout and work-related stressors

Participants with burnout showed a statistically significant lower mean for control than peers without burnout $[\mathrm{t}-(502)=5.521, p<0.001]$ (Table 2). Since lower scores indicate low control, this is an indication of lower control among participants with burnout. There was no 
Table 4. Proportion of participants with burnout according to categories of social support and sources of support among workers exposed to workplace violence over the past $12 \mathrm{mo}$

\begin{tabular}{|c|c|c|c|}
\hline & Total number & Number with mild/severe burnout & Proportion \\
\hline \multicolumn{4}{|l|}{ Support* } \\
\hline Received support following WPV & 152 & 65 & 42.8 \\
\hline No support following WPV & 24 & 12 & 50.0 \\
\hline Felt no need for help & 147 & 46 & 31.3 \\
\hline \multicolumn{4}{|l|}{ Sources of support ${ }^{\text {a) }}$} \\
\hline Support from supervisor & 84 & 29 & 34.5 \\
\hline Support from co-worker & 98 & 45 & 45.9 \\
\hline Support from someone outside workplace & 33 & 12 & 36.4 \\
\hline
\end{tabular}

${ }^{*} p$-value $<0.05$. ${ }^{\text {a) }}$ Since the participants may have had several sources of support, the percentages may not add up to 100.

statistically significant association between burnout on the one hand and either demands or support on the other.

\section{Association between WPV exposure over the past 12 mo and burnout}

An association was found between exposure to WPV and burnout, even after control for possible confounding by demographic/job characteristics and work stressors. As indicated by the adjusted odds ratios (Table 3), participants not exposed to WPV over the past $12 \mathrm{mo}$ $(\mathrm{OR}=0.533, p<0.05)$ were at lower risk of burnout than their exposed peers.

Association between burnout and social support among participants exposed to WPV over the past 12 mo

As shown in Table 4, participants who had been exposed to WPV and lacked social support showed a higher proportion of burnout $(50.0 \%)$ than peers exposed to WPV who had received support $(42.8 \%)$. This association showed statistical significance $(p$-value $<0.05)$ in the chisquare test. Participants exposed to WPV who had received support from a supervisor $(34.5 \%)$, co-worker $(45.9 \%)$ or someone outside the workplace $(36.6 \%)$ tended to exhibit lower proportions of burnout than peers without such support (50\%), although the differences were not statistically significant.

\section{Discussion}

Cross-sectional data were analyzed to explore the association between WPV and burnout, and whether social support moderates the relationship, among drivers and conductors in road passenger transport in Maputo City, Mozambique.

The findings indicate that about three quarters of participants had burnout symptoms, and that the proportion was even greater among workers exposed to WPV. The prevalence of severe burnout was $3.6 \%$ and mild burnout $30.1 \%$, indicating that burnout is a public health problem in the sector. Although comparable data in similar settings are lacking, the current figures are similar to those from studies of workers in education and human services (hospitals, social security offices, institutions for the severely disabled, etc.), where figures for severe burnout of $2-3 \%$ and for mild burnout of $25-39 \%$ have been reported $^{9,30)}$.

Exposure to WPV was found to be significantly associated with burnout, which suggests that it may be determined by factors independent of the other possible causes of burnout controlled for in this study. This finding supports other work linking burnout to work stressors, including WPV ${ }^{18,19)}$. Although such associations have been reported in the current and previous studies, a crosssectional study design does not permit causal interpretation. One explanation for the finding may be that WPV may be a work stressor that leads to burnout in the longer term. Another possible explanation is that workers with burnout perform their jobs poorly ${ }^{34)}$, and their failure to meet passenger expectations increases vulnerability to abuse. This notion is supported by a recent study in the transport sector $^{35)}$. Thus, there is a need for more stringent study designs to ascertain the mechanisms linking burnout to WPV.

As hypothesized, burnout was found to be more common among workers exposed to WPV lacking subsequent social support than among peers who had received support following WPV exposure. The same trend was found for the different sources of support (supervisor, co-worker, and person outside the workplace), although it was without significance for any specific source. This finding may reflect circumstances in which the adverse consequences of burnout are reduced by the direct and/or buffering effects of social support ${ }^{36,37)}$. This has important implications for the management of burnout in sectors where the prevalence of WPV is high. A support network is of fundamental importance for all victims of WPV in order to reduce the potential risk of burnout. The 
results also reveal that the participants exposed to WPV who stated that they did not need support showed the lowest proportion of burnout. This finding is difficult to reconcile and calls for further research, probably of a qualitative nature, to obtain an in-depth understanding of the perceived need for support among workers in the transport sector.

The study has some potential weaknesses and strengths that warrant acknowledgement. One strength is that it was possible to control potential confounders, e.g. age, occupation and work stressors that are known to correlate with both burnout and WPV ${ }^{15-17,38)}$. A weakness of the study is that its design was cross-sectional, which made it impossible to draw causal conclusions. Also, burnout is strongly associated with depression, and the current work did not incorporate measures to control for depression ${ }^{39}$. As such, the burnout indicator in this study might reflect depression. Finally, the $100 \%$ response rate in the study, though ideal, is unusual, and warrants discussion over whether it is a strength or a weakness, or both. A number of factors acting together may have accounted for the $100 \%$ response. The participants may have found the topic highly relevant. The project organization, information dissemination regarding the study and its objectives, training of data collection personnel, an emphasis on ethical considerations, such as privacy and the guarantee of confidentiality, may all have boosted the response rate. The incentive package offered to participants may have been a major contributor to the total response rate; that is, all participants needing psychological support or medical care due to hearing, vision or sleep problems were referred to government hospitals, where treatment is free of charge. These factors notwithstanding, the possibility of participants being coerced into participating in the study cannot be entirely ruled out. It is plausible that employers may have signalled that participation was obligatory when informing participants of the study. The exact effects of these factors are difficult to assess. The incentive package may have encouraged participants to overemphasize workrelated stressors, whereas possible coercion by employers may have discouraged them to report violence in the workplace. The magnitudes of our estimates therefore need to be interpreted with caution. It is, however, important to note that the hypothesized relationships were confirmed in many respects, which indicates that the results are valid to some degree.

In conclusion, the study suggests that burnout is a public health problem among workers in the transport sector in Mozambique, and may be closely and independently linked to WPV. Social support appears to buffer or moderate the effect of WPV on burnout. This has implications for policy in the workplace. Strategies and guidelines should be put in place to support workers following WPV, as these may prove to be of paramount importance in reducing burnout and the other psychosocial consequences of WPV. More robust studies of the associations between psychosocial job stressors and health, particularly in Sub-Saharan Africa, are warranted to further substantiate our findings.

Acknowledgments: The study was financially supported by Mozambique Distribuidora (LDA) in Maputo, Mozambique.

\section{References}

1) Maslach Leiter MP. Early predictors of job burnout and engagement. J Appl Psychol 2008; 93: 498-512.

2) Maslach C, Shaufeli WB, Leiter, MP. Job Burnout. Annu Rev Psychol 2001; 52: 397-422.

3) Grau Martín A, Flichtentrei D, Suñer R, Prats M, Braga F. Influence of personal, professional and cross-national factors in burnout syndrome in Hispanic Americans and Spanish health workers. Rev Esp Salud Publica 2009; 83: 215-3.

4) Surgenor LJ, Spearing RL, Horn J, Beautrais AL, Mulder RT, Chen P. Burnout in hospital-based medical consultants in the New Zealand public health system. N Z Med J 2009; 122: 11-8.

5) Ashtari Z, Farhady Y, Khodaee MR. Relationship between job burnout and work performance in a sample of Iranian mental health staff. Afr J Psychiatry (Johannesbg) 2009; 12: 71-4.

6) Shanafelt TD, West CP, Sloan JA, et al. Career fit and burnout among academic faculty. Arch Intern Med 2009; 169: 990-5.

7) Gabbe SG, Webb LE, Moore DE, Harrell FE Jr, Spickard WA Jr, Powell R Jr. Burnout in medical school deans: an uncommon problem. Acad Med 2008; 83: 476-82.

8) Tsai FJ, Chan CC. Occupational stress and burnout of judges and procurators. Int Arch Occup Environ Health 2009; $4: 4$.

9) Ahola K, Toppinen-Tanner S, Huuhtanen P, Koskinen A, Väänänen A. Occupational burnout and chronic work disability: an eight-year cohort study on pensioning among Finnish forest industry workers. J Affect Disord 2009; 115: 150-9.

10) Cunradi CB, Chen MJ, Lipton R. Association of occupational and substance use factors with burnout among Urban transit operators. J Urban Health 2009; 86: $562-70$.

11) Borritz M, Rugulies R, Bjorner JB, Villadsen E, Mikkelsen OA, Kristensen TS. Burnout among employees in human service work: design and baseline findings of the PUMA study. Scand J Public Health 2006; 34: 49-58.

12) Ahola K, Kivimäki M, Honkonen T, et al. Occupational burnout and medically certified sickness absence: the population-based sample of Finnish employees. J Psychosom Res 2008; 64: 185-93.

13) Garrosa E, Moreno-Jimenez B, Liang Y, González JL. The relationship between socio-demographic variables, job stressors, burnout, and hardy personality in nurses: an exploratory study. Int J Nurs Stud 2008; 45: 41827. 
14) Kokkinos CM. Job stressors, personality and burnout in primary school teachers. Br J Educ Psychol 2007; 77: 229-43.

15) Ahola K, Honkonen T, Isometsä E et al. Burnout in the general population-Results from the Finnish Health 2000 Study. Soc Psychiatry Psychiatr Epidemiol 2006; 41: 11-7.

16) Ahola K, Honkonen $T$, Virtanen M, Aromaa A, Lönnqvist $\mathrm{J}$. Burnout in relation to age in the adult working population. J Occup Health 2008; 50: 362-5.

17) Kalimo R, Pahkin K, Mutanen P, Toppinen-Tanner Sl. Staying well or burning out at work: work characteristics and personal resources as long-term predictors. Work and Stress 2003; 17: 109-22.

18) Mathisen GE, Einarsen S, Mykletun R. The occurrences and correlates of bullying and harassment in the restaurant sector. Scand J Psychol 2008; 49: 59-68.

19) Estryn-Behar M, van der Heijden $B$, Camerino D, et al. Violence risks in nursing - results from the European NEXT Study. Occup Med (Lond) 2008; 58: 107-14.

20) Cohen S, Wills T A. Stress, social support, and the buffering hypothesis. Psychol Bull 1985; 98: 310-57.

21) Lazarus RS. Emotion adaptation. Oxford: Oxford univ. Press; 1991.

22) McCubbin HI, Petterson J. The family stress process: the double ABCX model of adjustment and adaptation. Marriage and family review 1983; 6: 7-37.

23) Rankin SH, Monahan P. Great expectations: perceived social support in couples experiencing cardiac surgery. Family Relations 1991; 40: 297-302.

24) House JS. Work Stress and social support. Reading, MA: Addison-Wesley; 1985.

25) Couto M T, Lawoko S, Svanstrom L.Violence against drivers and conductors in the road passenger transport sector in Maputo, Mozambique. Afr Safety Promotion J 2009; 7: 17-36.

26) Resultados do $3^{\circ}$ recenseamento geral da população habitação. (Results of 3rd general population and housing census). Maputo: Instituto Nacional de Estatística (INE), 2010.

27) Maslach C, Jackson S, Leiter MP. Maslach Burnout Inventory Manual. $3^{\text {rd }}$ edition. Mountain View (California): CCP Inc; 1996. p. 19-26.

28) Schutte N, Toppinen S, Kalimo R, Schaufeli WB. The factorial validity of the Maslach Burnout Inventory-
General Survey (MBI-GS) across occupational groups and nations. J Occup Organ Psychol 2000; 73: 53-66.

29) Langballe EM, Falkum E, Innstrad ST, Aasland OG. The factorial validity of the Maslach Burnout InventoryGeneral Survey in representative samples of eight different occupational groups. J Career Assessment 2006; 14: 370-84.

30) Honkonen T, Ahola K, Pertovaara M, et al. The association between burnout and physical illness in the general population-results from the Finnish Health 2000 Study. Journal of Psychosomatic Research 2006; 61: 59-66.

31) Arnetz JE, Arnetz BB. Implementation and evaluation of a practical intervention programme for dealing with violence towards health care workers. J adv nurs 2000; $31,668-80$.

32) Menckel E, Viitasara E. Threats and violence in Swedish care and welfare magnitude of the problem and impact on municipal personnel. Scand J Caring Sci 2002; 16 : 376-85.

33) Karasek R, Theorell T. Healthy work: stress, productivity, and the reconstruction of working life. New York: Basic Books; 1990.

34) Pedrini L, Magni LR, Giovannini C, et al. Burnout in non hospital psychiatric residential facilities. Psychiatr Serv 2009; 60: 1547-51.

35) Boyd C. Customer violence and employee health and Safety, in Work, employment and society, Sage 2002; 16: 151-69.

36) Ben-Zur H, Michael K. Burnout, social support, and coping at work among social workers, psychologists, and nurses: the role of challenge/control appraisals. Soc Work Health Care 2007; 45: 63-82.

37) Sundin L, Hochwälder J, Bildt C, Lisspers J. The relationship between different work-related sources of social support and burnout among registered and assistant nurses in Sweden: a questionnaire survey. Int J Nurs Stud 2007; 44: 758-69.

38) Chappel D, Di Martino V. Violence at work. Geneva: International Labor Office; 2006.

39) Ahola K, Honkonen T, Isometsä E, et al. The relationship between job-related burnout and depressive disorders results from the Finnish Health 2000 Study. J Affect Disord 2005; 88: 55-62. 